\title{
Seismic activity around the northern neighbor of the 2011 off the Pacific coast of Tohoku Earthquake with emphasis on a potentially large aftershock in the area
}

\author{
Masahiro Kosuga and Kazutoshi Watanabe \\ Earthquake and Volcano Observatory, Graduate School of Science and Technology, Hirosaki University, Hirosaki 036-8561, Japan
}

(Received April 7, 2011; Revised June 2, 2011; Accepted June 3, 2011; Online published September 27, 2011)

\begin{abstract}
We investigated the seismic activity around the northern neighbor of the 2011 off the Pacific coast of Tohoku Earthquake $\left(M_{\mathrm{W}} 9.0\right)$ with special attention to a potential large aftershock in the area. We obtained a combined data set by adding our manually-picked locations to the catalog locations by the Japan Meteorological Agency. The hypocenter distribution delineates active and inactive bands of seismicity. The band of low seismicity corresponds to a zone of a large seismic slip, indicating that aftershocks occurred in peripheral neighbors of the mainshock asperity. The broad band of active seismicity along the coast corresponds to the zone of a large postseismic slip, suggesting the enhancement of the aftershock activity by the slip. Although the northern neighbor of the mainshock fault is a favored region of increased seismicity, as shown from a Coulomb stress calculation, no significant seismic activity is observed within the potential source area except along the Japan Trench and the SW corner. This implies that the zone of interplate moment release by previous large earthquakes and the subsequent slow slip acted as a barrier to the migration of both the mainshock rupture and aftershock activity. However, an aftershock area in the zone may reflect inhomogeneous moment release by past seismic and aseismic sequences.
\end{abstract}

Key words: 2011 off the Pacific coast of Tohoku Earthquake, hypocenter distribution, aftershock activity, postseismic slip.

\section{Introduction}

The 2011 off the Pacific coast of Tohoku Earthquake $\left(M_{\mathrm{W}} 9.0\right)$ is the largest earthquake recorded in Japan, and it caused indescribably severe damage mainly by a huge tsunami along the coast from the Tohoku to the Kanto district in Honshu Island. The earthquake is megathrust faulting along the subduction zone plate boundary between the Pacific and North American plates. Figure 1 is a map view of northeastern Japan showing the source area of the 2011 Tohoku Earthquake. The length of the rupture area extends nearly $500 \mathrm{~km}$ along the Japan Trench. The aftershock distribution of large earthquakes is essential for estimating the extent of a source fault. This information is of particular importance when assessing the location of future large aftershocks that may be hazardous to areas severely damaged by a mainshock. Typically, large aftershocks occur in neighboring areas of the mainshock fault. For example, in the case of the 2004 Sumatra earthquake $\left(M_{\mathrm{W}} 9.2\right)$, the largest aftershock $\left(M_{\mathrm{W}} 8.6\right)$ occurred about three months later in the neighbor asperity located to the SSE of the mainshock fault. Therefore, the largest aftershock of the 2011 Tohoku Earthquake is expected to occur either in the northern part or in the southern part of the mainshock fault. The Headquarters for Earthquake Research Promotion (2009) have

Copyright (C) The Society of Geomagnetism and Earth, Planetary and Space Sciences (SGEPSS); The Seismological Society of Japan; The Volcanological Society of Japan; The Geodetic Society of Japan; The Japanese Society for Planetary Sciences; TERRAPUB.

doi:10.5047/eps.2011.06.006 evaluated the occurrence probability of a future 'Northern Sanriku' earthquake (purple polygon in Fig. 1). The occurrence probabilities in the area over the next 30 years are $0.3 \%-10 \%$ for the case of $M \sim 8.0$ event and $90 \%$ for the case of $M 7.1-7.6$ event. Northern Sanriku has experienced large disastrous earthquakes such as the 1968 Tokachi-oki $\left(M_{\mathrm{W}} 8.2\right)$ and the 1994 Sanriku-haruka-oki $\left(M_{\mathrm{W}} 7.7\right)$ earthquakes. Thus, it is important to investigate the seismic activity around the northern neighbor of the mainshock fault. In this study, we will investigate the activity using a precise hypocenter distribution from a combined data set of the local seismic network of Hirosaki University and the catalog location of the Japan Meteorological Agency (JMA).

\section{Hypocenter Location}

We located earthquakes using waveform data collected from stations shown in Fig. 2. The stations belong to the Hirosaki, Tohoku, and Hokkaido Universities, the JMA, the local government of Aomori prefecture, and Hi-net. We selected events by visually inspecting all event files detected by a trigger function of the WIN system (Urabe and Tsukada, 1992) commonly used in seismological observatories of Japanese universities. Then we manually picked the arrival times of $P$ - and $S$-waves and located events using a 1-D velocity structure similar to that used for the routine hypocenter location of Tohoku University (Hasegawa et al., 1978). We modified the Moho depth to $27 \mathrm{~km}$ for the location of oceanic events. Because of the power loss in the entire Tohoku district after the mainshock and the difficulty 


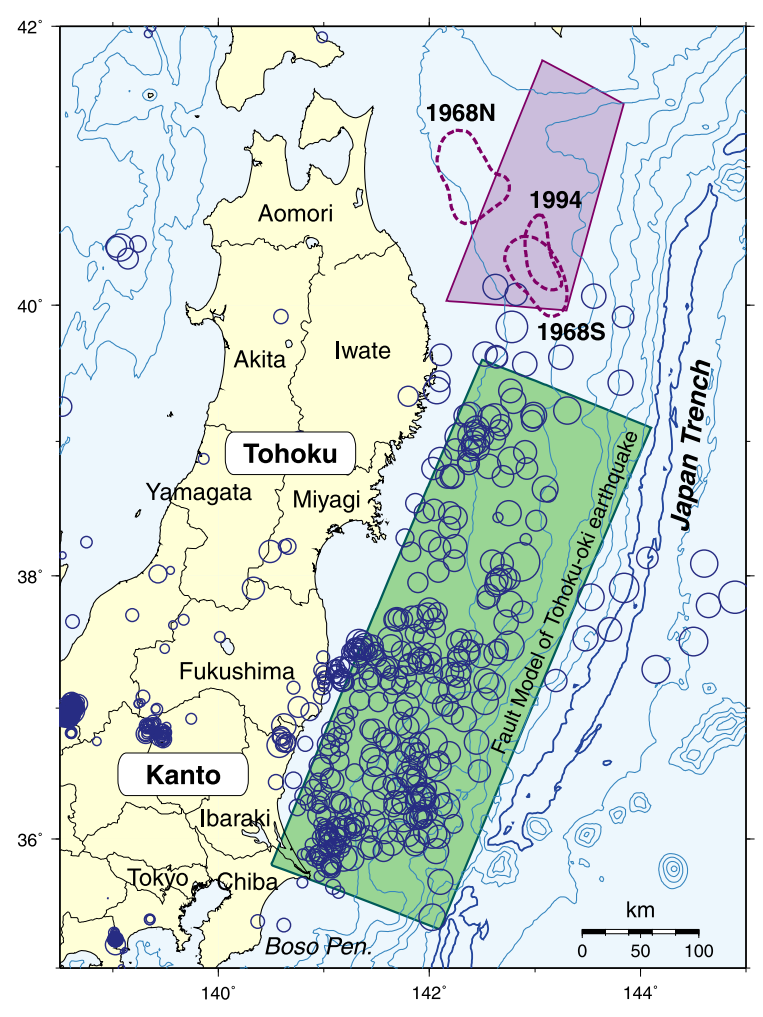

Fig. 1. Map of northeastern Japan showing the source areas of the 2011 off the Pacific coast of Tohoku Earthquake together with the past and future earthquakes. The green rectangle represents a fault model of the 2011 Tohoku Earthquake (Earthquake Research Institute, 2011). The broken lines indicate the asperities of the 1968 Tokachi-oki earthquake $\left(M_{\mathrm{W}} 8.2,1968 \mathrm{~N}\right.$ and $\left.1968 \mathrm{~S}\right)$ and the 1994 Sanriku-haruka-oki earthquake $\left(M_{\mathrm{W}} 7.7\right)$ (Yamanaka and Kikuchi, 2004). The purple polygon is the potential source area where the Headquarters for Earthquake Research Promotion (2009) evaluated the occurrence probability. The circles denote hypocenters of aftershocks located by the JMA for a one-day period from the occurrence of the 2011 Tohoku Earthquake.

in phase picking for the period of extremely active seismicity, our location data maintain a certain level after March 16, 2011. The data have some limitations because it was urgent to monitor seismic activity in the location. We skipped the location of small earthquakes. The threshold is approximately $M \sim 3.2$ for events beneath the ocean (Fig. 3(a)). We limited the number of picks up to approximately 20 for $P$-waves and approximately 10 for $S$-waves. We utilized stations mainly in the Iwate prefecture for the location of oceanic events.

Figure 2(a) compares the hypocenter distribution of our data and the JMA catalog for a two-day period from March 16, 2011. For inland earthquakes, the JMA catalog includes more events than our location, but the situation is reversed for the oceanic events. The box in the inset map of Fig. 3(a) shows a comparison of magnitude-frequency distribution for the events. Our catalog contains more events with magnitudes smaller than 3.5. The total number of events is 421 in our catalog and 235 in the JMA catalog. The $b$-value from our data, 0.68 , is significantly lower than those obtained in inland areas but consistent with those from events far east off the Tohoku district (Hirose et al., 2002). The average nominal location errors from events shown in the box in Fig. 3(a) are $0.030^{\circ}$ for latitude and $0.058^{\circ}$ for longitude.

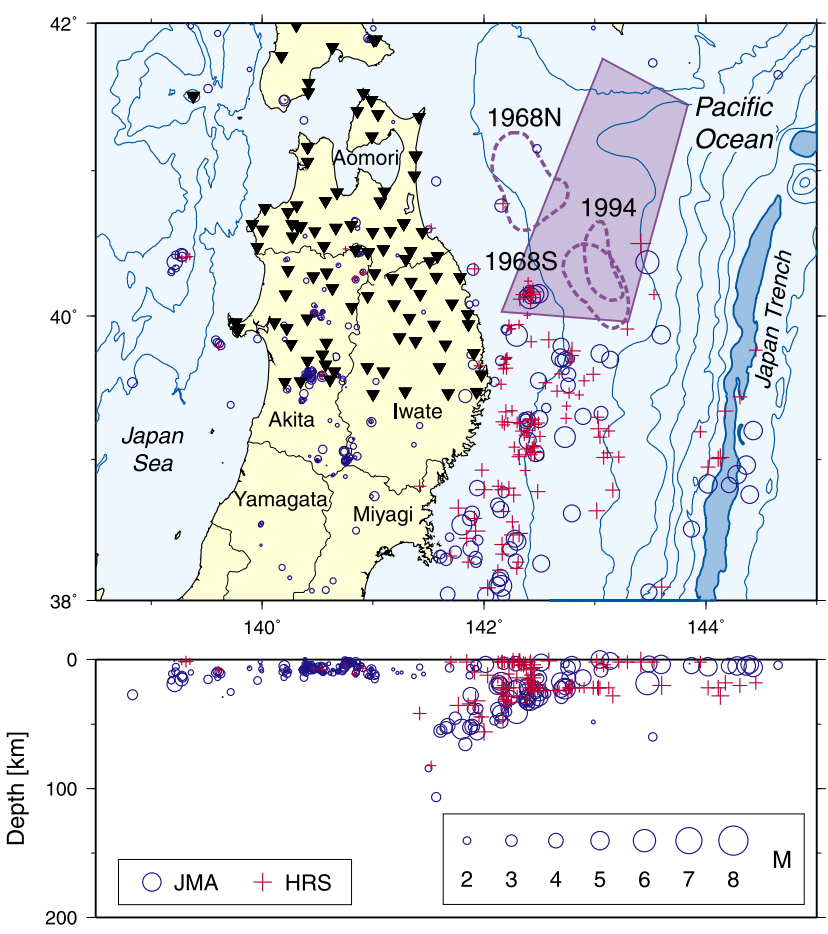

Fig. 2. Map of northeastern Tohoku showing the hypocenter distribution of the 2011 Tohoku Earthquake for a two-day period from March 16, 2011. The circles and crosses denote hypocenters of aftershocks located by Hirosaki University and the JMA. The solid triangles indicate the seismographic stations used in this study. The broken lines and the purple polygon are the same as shown in Fig. 1.

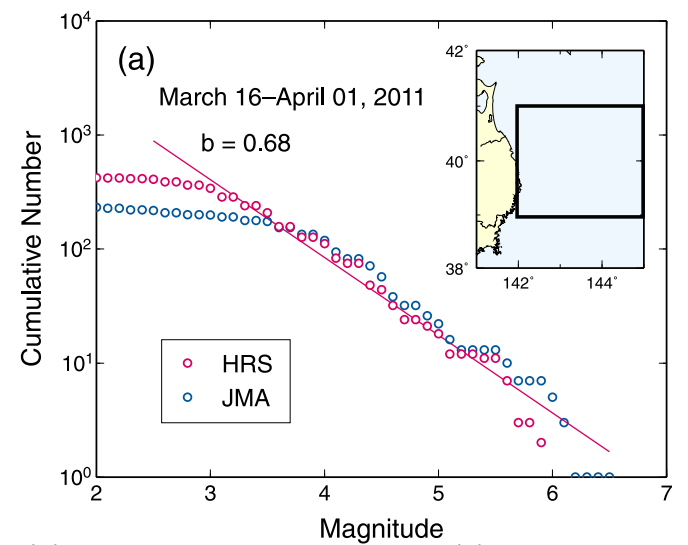

(b)

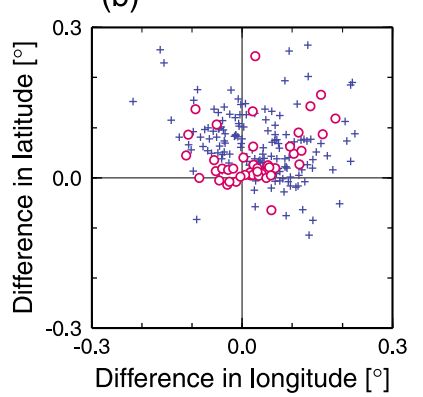

(c)

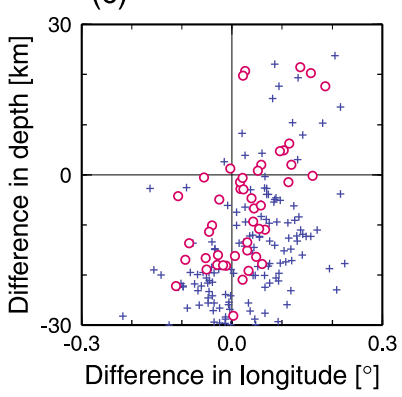

Fig. 3. (a) Comparison of magnitude-frequency distribution between our locations (red circles) and the JMA catalog (blue circles). The sampling area is shown as the box in the inset map. (b) and (c) Deviation of our source location relative to the JMA catalog for the events in the range of the inset map. The red circles show earthquakes to the north of $39^{\circ} \mathrm{N}$. 
(a) 2011

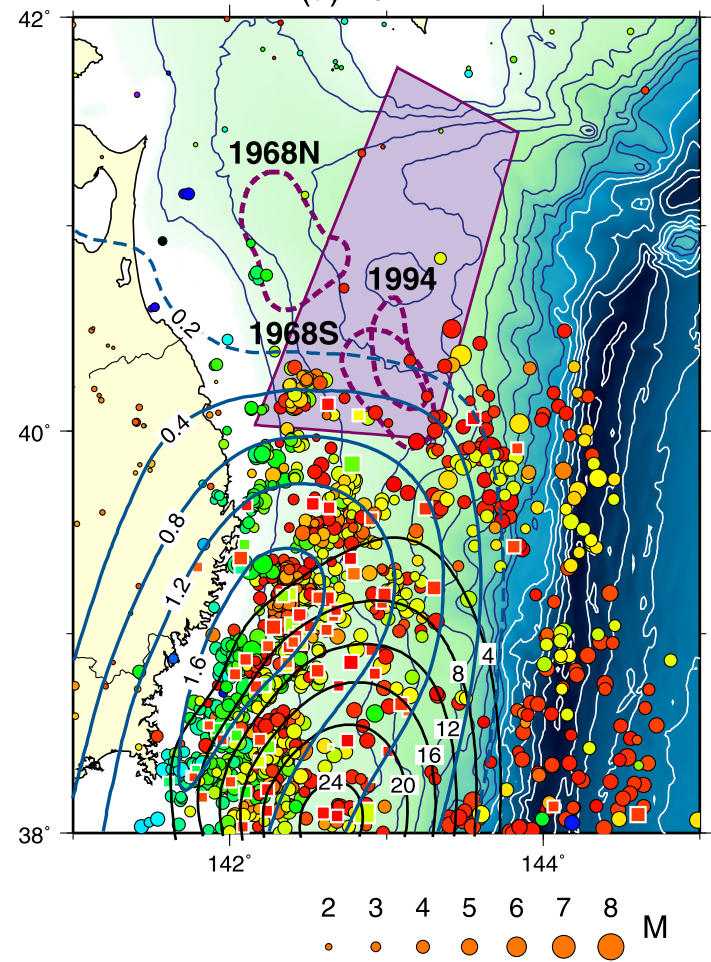

(b) 1989-1995

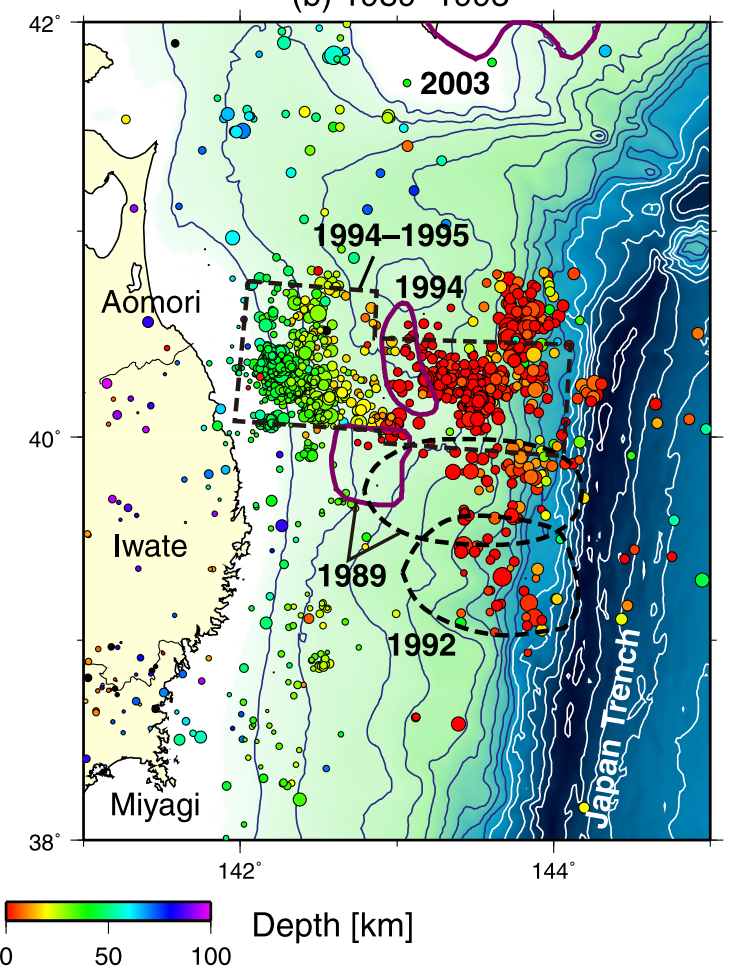

Fig. 4. (a) Epicenter distribution of combined data for a 21-day period from the mainshock. The immediate one-day aftershocks are indicated by squares. The black and blue contour lines are the coseismic and postseismic slip distributions as of May 12, 2011 (Geospatial Information Authority of Japan, 2011). Unit is in $\mathrm{m}$. The purple polygon and lines are the same as in Fig. 1. (b) One-month aftershock distribution of the 1994 Sanriku-haruka-oki earthquake from the JMA catalog. The purple lines delineate the location of asperities of the earthquakes in 1989, 1994, and 2003. The broken lines show the areas of postseismic slips (Heki et al., 1997; Kawasaki et al., 1998, 2001).

Figures 3(b) and (c) show the deviation of location relative to the JMA catalog. Although there is a systematic bias in our data probably because of the effect of the subducting slab with high seismic velocity, the epicenter deviation is generally smaller than $0.1^{\circ}$, provided the location is limited to the north of $39^{\circ} \mathrm{N}$. Thus, our data are suitable for discussing the seismicity of oceanic events in the northern part of the aftershock zone. Because our catalog does not cover the period before March 15, 2011, we combined the JMA data during this period with our data of up to April 01, 2011. We think this combined data provides the best manually-located hypocenters for the northern part of the aftershock zone.

\section{Aftershock Distribution around the Northern Neighbor of Tohoku-oki Earthquake}

Figure 4(a) shows the hypocenter distribution for a 21day period from the occurrence of the mainshock. The range of aftershock distribution reaches beyond $40^{\circ} \mathrm{N}$ to the north, near the pacific coast to the west, and around the trench axis to the east. The active band of seismicity is located between $142^{\circ}$ and $143^{\circ} \mathrm{E}$ and along the Japan Trench. Seismicity is significantly lower between $143^{\circ} \mathrm{E}$ and the Trench. The contour lines in Fig. 4(a) are the coseismic and postseismic slip distributions on the plate boundary estimated from the GPS data (Geospatial Information Authority of Japan, 2011). Some researchers estimated a large coseismic slip near the trench axis (Hayes, 2011; Shao et al., 2011). Although the location of the asperity is under
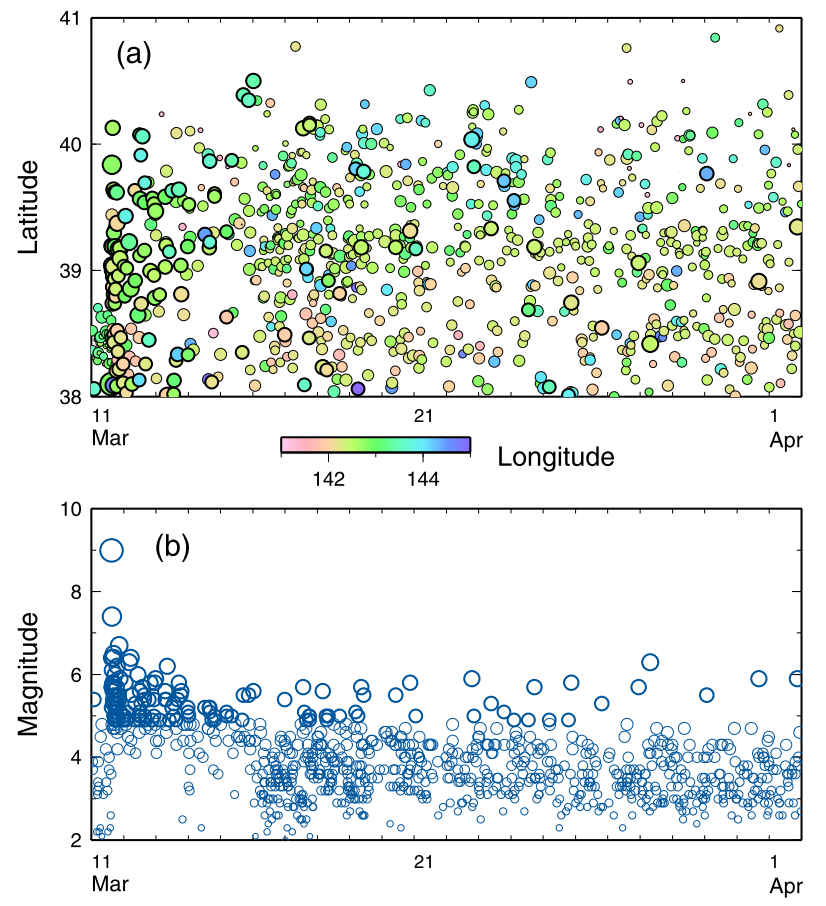

Fig. 5. Temporal variation of (a) latitude and (b) magnitude of aftershocks. The size of the circles corresponds to the earthquake magnitude. Events with magnitudes equal to or greater than 5 are indicated by dark outlines. The colors in (a) represent the longitude of events. The apparent increase in smaller shocks after March 16, 2011, is because of the switching of the catalog from the JMA to Hirosaki University. 
debate, the area of low seismicity roughly corresponds to the asperity. The active band of seismicity to the west correlates well with the zone of large postseismic slip. This suggests that the postseismic slip enhances the aftershock activity. However, not all the aftershocks occurred on the plate boundary where the postseismic slip is assumed to have taken place.

There are several active clusters located to the east off the northern Iwate prefecture $\left(\sim 40.2^{\circ} \mathrm{N}, 142.4^{\circ} \mathrm{E}\right)$, off the central Iwate prefecture $\left(\sim 39.6^{\circ} \mathrm{N}, 142.6^{\circ} \mathrm{E}\right)$, off the southern Iwate prefecture $\left(\sim 39.2^{\circ} \mathrm{N}, 142.3^{\circ} \mathrm{E}\right)$, and off the northern Miyagi prefecture $\left(\sim 38.4-38.8^{\circ} \mathrm{N}, 141.8-142.4^{\circ} \mathrm{E}\right)$. Figure 5 displays a temporal change in seismicity. The aftershock zone expanded to the north on March 15, 2011, when some large ( $M \sim 5.0)$ events occurred. The seismicity of large events shows a spatiotemporal variation. After March 24, 2011, the seismic activity decreases in the range to the north of $39.5^{\circ} \mathrm{N}$ while that in the range $38.5^{\circ}-39.5^{\circ} \mathrm{N}$ is apparently unchanged. Seismic activity of active clusters mentioned above repeated the short-term activation. The maximum magnitude shows little temporal variation after March 14, 2011 (Fig. 5(b)). However, the magnitude of the second largest event in a short period of a few days decreases gradually after March 27, 2011, forming a magnitude gap.

\section{Discussion}

Several authors have evaluated the Coulomb stress change due to the rupture of the 2011 Tohoku Earthquake (Hiratsuka and Sato, 2011; Lay et al., 2011; Toda et al., 2011). For a thrust fault with the same geometry as the mainshock, the expected areas of increased seismicity are located around both edges in the strike direction of the mainshock fault and the area of outer rise. The southern part of the potential seismic source area of the Northern Sanriku earthquake (the polygon in Fig. 4(a)) is in the favored region of increased seismicity. However, there is no significant increase in this part except on the eastern edge and the SW corner. This may be related to the past history of seismic moment release by the three major interplate earthquakes in $1989\left(M_{\mathrm{W}} 7.4\right), 1992\left(M_{\mathrm{W}} 6.9\right)$, and $1994\left(M_{\mathrm{W}} 7.7\right)$, i.e., the Sanriku-haruka-oki earthquake. Kawasaki et al. (1998, 2001) pointed out that slow slips followed the 1989 and 1992 events. The postseismic slip of the 1994 event was clearly detected by GPS and lasted more than one year (Heki et al., 1997; Nishimura et al., 2000). The areas of postseismic slip are illustrated in Fig. 3(b). Kawasaki et al. $(1998,2001)$ argued that the accumulated seismic moment in a region from $39.0^{\circ} \mathrm{N}$ to $40.6^{\circ} \mathrm{N}$ along the Japan Trench was considerably released by the seismic and aseismic sequences in the period between 1989 and 1995. This zone possibly acted as a barrier to both the rupture of the 2011 Tohoku Earthquake and the aftershock migration.

Figure 4(a) shows broad zones of seismicity far east off the northern Iwate prefecture $\left(\sim 39.6^{\circ}-40.5^{\circ} \mathrm{N}, 143^{\circ}-\right.$ $\left.144^{\circ} \mathrm{E}\right)$ and near the trench axis. A similar increase in seismicity to the west of the trench axis was observed in the aftershock distribution of the 1994 Sanriku-haruka-oki earthquake (Fig. 4(b)). Uchida et al. (2004) found an increased activity of small repeating earthquakes prior to the occur- rence of the 1989, 1992, and 1994 events. They interpreted that accelerated quasi-static slips caused stress concentrations at the asperities of mainshocks. If the same mechanism holds for the aftershock activity of the 2011 Tohoku Earthquake, increased seismicity far east off the northern Iwate prefecture is caused by the migration of the postseismic slip. The contour lines of the postseismic slip reach the area of increased aftershock activity (Fig. 4(a)). However, this activated area partly overlaps the zone of the aseismic slip of the 1989 earthquake (Fig. 4(b)). This discrepancy may be explained by either the spatially inhomogeneous interplate moment release by past seismic and aseismic sequences or by an inhomogeneous postseismic slip distribution of the 2011 Tohoku Earthquake.

Another example of triggering by a postseismic slip is the 2003 Tokachi-oki earthquake $\left(M_{\mathrm{W}} 8.3\right)$ that took place at the SW corner of the Kuril arc (Fig. 4(b)). An earthquake doublet with $M 7.0$ and $M 6.9$ was triggered by the slow slip that migrated more than $100 \mathrm{~km}$ to NE from the source area of the Tokachi-oki event (Murakami et al., 2006). The Geospatial Information Authority of Japan is monitoring postseismic slip distribution using the data of the nationwide GPS network (GEONET). As of May 12, 2011, the northernmost boundary of the postseismic slip is found to migrate to the southern part of the potential source area (Fig. 4(a)). The monitoring of postseismic slip together with seismicity change around the potential source area is important in the prediction of future large earthquakes.

\section{Conclusions}

The aftershock distribution of the 2011 Tohoku Earthquake clearly shows the existence of parallel zones of active and inactive seismicity along the Japan Trench off the northern part of the Tohoku district. The location of the inactive zone seems to correspond to the asperity. The active band of seismicity along the coast correlates well with the zone of the postseismic slip, suggesting that the slip enhances the aftershock activity. The aftershocks migrated to the north but seismicity in the potential source area of the Northern Sanriku earthquake is low except on the eastern edge and the SW corner. The zone around the southern neighbor of the potential source has released seismic moment by the seismic and aseismic sequences in the period between 1989 and 1995. This zone possibly acted as a barrier to both the rupture of the 2011 Tohoku Earthquake and the aftershock migration. Active aftershock seismicity in the zone may represent spatially inhomogeneous moment release by the past sequence or heterogeneous postseismic slip distribution of the 2011 Tohoku Earthquake.

Acknowledgments. We used hypocentral parameters of the JMA catalog. The catalog was prepared by the JMA and the Ministry of Education, Culture, Sports, Science and Technology in Japan. The hypocenters of the catalog were determined by the data of JMA, NIED, Hirosaki University, Tohoku University, Hokkaido University, University of Tokyo, and Aomori Prefecture. We are very grateful to members of the above organizations. Constructive comments from two anonymous reviewers were helpful in revising the manuscript. All figures were drawn with the Generic Mapping Tools (GMT) developed by Wessel and Smith (1998). 


\section{References}

Earthquake Research Institute, Source process and strong ground motion for the 2011 off the Pacific coast of Tohoku Earthquake, http://outreach.eri.u-tokyo.ac.jp/ul/ EVENT/201103_Tohoku_Danwa_saigai.pdf, $2011 \quad$ (in Japanese).

Geospatial Information Authority of Japan, Postseismic slip distribution model inferred from GEONET data, http://www.gsi.go.jp/ cais/topic110315.2-index-e.html, 2011.

Hasegawa, A., N. Umino, and A. Takagi, Double-planed structure of the deep seismic zone in the northeastern Japan arc, Tectonophysics, 47, 43-58, 1978.

Hayes, G. P., Rapid source characterization of the $2011 M_{\mathrm{w}} 9.0$ off the Pacific coast of Tohoku Earthquake, Earth Planets Space, 63, this issue, 529-534, 2011.

Headquarters for Earthquake Research Promotion, Evaluation of occurrence potentials of subduction-zone earthquakes, http: //www.jishin.go.jp/main/p_hyoka02_kaiko.htm, 2009 (in Japanese).

Heki, K., S. Miyazaki, and H. Tsuji, Silent fault slip following an interplate thrust earthquake at the Japan Trench, Nature, 386, 595-597, 1997.

Hiratsuka, S. and T. Sato, Alteration of stress field brought about by the occurrence of the 2011 off the Pacific coast of Tohoku Earthquake $\left(M_{\mathrm{w}}\right.$ 9.0), Earth Planets Space, 63, this issue, 681-685, 2011.

Hirose, F., A. Nakamura, and A. Hasegawa, $b$-value variation associated with the rupture of asperities-spatial and temporal distributions of $b$ value east off NE Japan, Zisin, 55, 249-260, 2002 (in Japanese).

Kawasaki, I., Y. Asai, and Y. Tamura, Interplate moment release in seismic and seismo-geodetic bands and the seismo-geodetic coupling in the Sanriku-Oki region along the Japan Trehch, Zisin, 50, S293-S307, 1998 (in Japanese).

Kawasaki, I., Y. Asai, and Y. Tamura, Space-time distribution of interplate moment release including slow earthquakes and the seismo-geodetic coupling in the Sanriku-oki region along the Japan trench, Tectonophysics, 330, 267-283, 2001.
Lay, T., C. J. Ammon, H. Kanamori, M. J. Kim, and L. Xue, Outer trenchslope faulting and the $2011 M_{\mathrm{w}} 9.0$ off the Pacific coast of Tohoku Earthquake, Earth Planets Space, 63, this issue, 713-718, 2011.

Murakami, M., H. Suito, S. Ozawa, and M. Kaidzu, Earthquake triggering by migrating slow slip initiated by $M 8$ earthquake along Kuril Trench, Japan, Geophys. Res. Lett., 33, L09306, doi:10.1029/2006GL025967, 2006.

Nishimura, T., S. Miura, K. Tachibana, K. Hashimoto, T. Sato, S. Hori, E. Murakami, T. Kono, K. Nida, M. Mishina, T. Hirasawa, and S. Miyazaki, Distribution of seismic coupling on the subducting plate boundary in northeastern Japan inferred from GPS observations, Tectonophysics, 323, 217-238, 2000.

Shao, G., X. Li, and C. Ji, Preliminary result of the Mar 11, 2011 $M_{\mathrm{W}} 9.1$ Honshu Earthquake (March 11, 2011) (Updated solution), http://www.geol.ucsb.edu/faculty/ji/ big_earthquakes/2011/03/0311/Honshu.html, 2011.

Toda, S., J. Lin, and R. S. Stein, Using the $2011 M_{\mathrm{w}} 9.0$ off the Pacific coast of Tohoku Earthquake to test the Coulomb stress triggering hypothesis and to calculate faults brought closer to failure, Earth Planets Space, 63, this issue, 725-730, 2011.

Uchida, N., A. Hasegawa, T. Matsuzawa, and T. Igarashi, Pre- and postseismic slow slip on the plate boundary off Sanriku, NE Japan associated with three interplate earthquakes as estimated from small repeating earthquake data, Tectonophysics, 385, 1-15, 2004.

Urabe, T. and S. Tsukada, win-A workstation program for processing waveform data from microearthquake networks, Prog. Abst. Seismol. Soc. Jpn., 2, P-41, 1992 (in Japanese).

Wessel, P. and W. H. F. Smith, New, improved version of the Generic Mapping Tools released, Eos Trans. AGU, 79, 579, 1998.

Yamanaka, Y. and M. Kikuchi, Asperity map along the subduction zone in northeastern Japan inferred from regional seismic data, J. Geophys. Res., 109, B07307, doi:10.1029/2003JB002683, 2004.

M. Kosuga (e-mail: mkos@cc.hirosaki-u.ac.jp) and K. Watanabe 